\title{
Flora da Usina São José, Igarassu, Pernambuco: Zingiberales
}

\author{
Flora of Usina São José, Igarassu, Pernambuco: Zingiberales
}

\author{
Naédja Kaliére Marques de Luna ${ }^{1,2}$, Edlley Pessoa $^{1}$ \& Marccus Alves ${ }^{1}$
}

\begin{abstract}
Resumo
Zingiberales está representada na flora brasileira por cerca de 300 espécies, ocorrendo na região Nordeste aproximadamente 100 espécies. O conhecimento sobre a ordem na Floresta Atlântica do estado de Pernambuco é incipiente, tendo esse estudo o objetivo de inventariar e caracterizar morfologicamente as espécies das Zingiberales da Usina São José, localizada em Igarassu. As coletas foram realizadas em oito expedições (entre Novembro de 2013 a Dezembro de 2014), além de visitas aos herbários HST, IPA, PEUFR e UFP. Na área de estudo foram encontradas uma espécie de Costaceae, três de Heliconiaceae, e sete de Marantaceae. Heliconia episcopalis e Maranta subterranea são citadas como novos registros para o estado. São apresentadas chave de identificação, descrições, comentários e ilustrações.
\end{abstract}

Palavras-chave: Costaceae, Floresta Atlântica, Florística, Heliconiaceae, Marantaceae.

\begin{abstract}
Zingiberales is represented in the Brazilian flora by almost 300 species, of which about 100 occur in the Northeast Region of the country. Zingiberales is poorly known in the Atlantic Forest of the state of Pernambuco and this study provides a taxonomic survey of the species found in the forest fragments of Usina São José, Igarassu. The field work was carried out in eight expeditions (from November 2013 to December 2014), as well as visits to herbaria: HST, IPA, PEUFR and UFP. In the studied area were found one species of Costaceae, three of Heliconiaceae and seven of Marantaceae. Heliconia episcopalis and Maranta subterranea are new records to the state. Identification key, descriptions, comments and illustrations are presented.
\end{abstract}

Key words: Costaceae, Atlantic Forest, Floristic, Heliconiaceae, Marantaceae.

\section{Introdução}

A Floresta Atlântica tem níveis elevados de diversidade e endemismo de espécies (Mittermeier et al. 1999), sendo citada como um dos hotsposts em biodiversidade, com alta prioridade de conservação (Myers et al. 2000). Originalmente cobria uma faixa contínua ao longo da costa atlântica brasileira e porções da Argentina e Paraguai, porém apenas $11 \%$ da floresta original permanece (Galindo Leal \& Câmara 2003; Ribeiro et al. 2009).

Zingiberales está inserida entre as Monocotiledôneas (APG III 2009) e tem como principais caracteres diagnósticos a presença de folhas com venação peni-paralelinérveas, padrão de prefoliação supervoluta, folhas e caules com câmaras de ar e ovário ínfero (Dahlgren et al. 1985; Kress 1990). É composta por oito famílias e possui distribuição pantropical, sendo principalmente encontrada em habitats como bordas de fragmentos florestais, áreas úmidas ou encharcadas e clareiras (Andersson 1998a,b,c,d; Kubitzki 1998; Larsen 1998a,b; Larsen et al. 1998).

Tem grande importância ecológica por ser um componente importante no sub-bosque de florestas tropicais, pelas interações com polinizadores (principalmente beija-flores e abelhas), e por algumas espécies terem suas espatas utilizadas como abrigo para diversas espécies de insetos e microorganismos (Endress 1994; Kennedy 2000; Specht \& Stevenson 2006; Alonso \& Sousa-Silva 2009). Algumas espécies apresentam potencial ornamental, alimentício ou medicinal (Almeida 1993; Andersson 1998a,b,c,d; Kubitzki 1998; Larsen 1998a; Larsen et al. 1998; Yoshida-Arns et al. 2002).

Está representada na flora brasileira pelas famílias Cannaceae, Costaceae, Heliconiaceae,

\footnotetext{
${ }^{1}$ Universidade Federal de Pernambuco, Lab. Morfo-Taxonomia Vegetal, Depto. Botânica, CCB, Av. Prof. Moraes Rêgo s/n, 50670-901, Recife, PE, Brasil.

${ }^{2}$ Autor para correspondência: naedjabio@yahoo.com.br
} 
Marantaceae e Zingiberaceae por cerca de 300 espécies, concentradas preferencialmente na Amazônia (40\%) e Floresta Atlântica (35\%), sendo 122 endêmicas do país (BFG 2015). Esses autores indicam para a Região Nordeste aproximadamente 100 espécies nestas famílias, e 30 para o estado de Pernambuco.

Apesar dos estudos de Yoshida-Arns et al. (2002) e Oliveira \& Leite (2007), o conhecimento sobre Zingiberales na região é incipiente, basicamente restrito a inventários florísticos pontuais (Souza et al. 2009; Nascimento et al. 2012). Este estudo é parte da série de monografias da Usina São José (Pernambuco) e objetiva inventariar e caracterizar morfologicamente as espécies de Zingiberales dos fragmentos florestais da área, contribuindo para o conhecimento da flora local com chave para identificação das espécies, descrições, ilustrações, e dados de distribuição geográfica dos táxons.

\section{Materiais e Métodos}

A Usina São José (USJ) localiza-se no litoral norte de Pernambuco, a cerca de $40 \mathrm{~km}$ de Recife $\left(7^{\circ} 40^{\prime}-7^{\circ} 55^{\prime} \mathrm{S}, 34^{\circ} 54^{\prime}-35^{\circ} 05^{\prime} \mathrm{W}\right)$, com área total de $280 \mathrm{Km}^{2}$, abrangendo os municípios de Abreu e Lima, Araçoiaba, Goiana, Igarassu (onde os fragmentos estudados estão inseridos), Itapissuma e Itaquitinga. Possui cerca de 100 fragmentos florestais com elevada diversidade vegetal (Alves et al. 2013), com diferentes áreas e formatos, sendo entre os fragmentos estudados o denominado "Chave" considerado médio (30200 ha), e "Piedade", "Zambana" e "Macacos", considerados grandes (> 200 ha) (Trindade et al. 2008).

Está situada no domínio da Floresta Atlântica e definida como Floresta Estacional Semidecidual de Terras Baixas (Thomas \& Barbosa 2008; IBGE 2012), sendo parte de uma região que abriga alguns dos maiores e mais importantes remanescentes de floresta no centro de endemismo de Pernambuco (Tabarelli et al. 2010).

Além das expedições de coleta realizadas durante a execução do Projeto Flora da Usina São José (2009-2012), adicionalmente oito expedições para coleta de material botânico foram realizadas, de novembro de 2013 a dezembro de 2014; os espécimes foram tratados de acordo com procedimentos usuais em estudos taxonômicos (Peixoto \& Maia 2013).

A identificação taxonômica foi possível com o auxílio de bibliografias especializadas:
Costaceae - Maas (1972); Heliconiaceae Andersson (1981b, 1985, 1992); e Marantaceae - Petersen (1890); Andersson (1977; 1981a; 1986); Yoshida-Arns et al. (2002) e YoshidaArns (2003). Também foram consultados os acervos dos herbários HST (Herbário Sergio Tavares - UFRPE), IPA, PEUFR e UFP (Thiers et al., continuamente atualizado). A terminologia morfológica segue Harris \& Harris (2001) e Gonçalves \& Lorenzi (2007). Para formas de crescimento de Heliconiaceae e Marantaceae seguiu-se Andersson (1981a,b; 1985) e para os habitats (borda, declive, sítio ripário e tabuleiro) de Floresta Atlântica adotou-se Silva et al. (2008).

$\mathrm{O}$ material foi incorporado ao herbário UFP e duplicatas enviadas aos herbários BHCB, CEPEC, HUEFS, JPB, R, RB e SP (Thiers et al., continuamente atualizado). Este estudo compõe a série de monografias elaboradas para a área (Pessoa \& Alves 2012; Araújo \& Alves 2013; Melo et al. 2013, entre outros). As espécies cultivadas nas propriedades das comunidades que habitam a área de estudo não foram incluídas nesse estudo, como Costus arabicus L. (Costaceae), Heliconia bihai (L.) L., Heliconia wagneriana Petersen (Heliconiaceae), Alpinia zerumbet (Pers.) B.L. Burtt \& R.M. Sm., e Hedychium coronarium J. Koenig, (Zingiberaceae).

\section{Resultados e Discussão}

Na USJ ocorrem três famílias pertencentes à ordem Zingiberales: Costaceae (uma espécie), Heliconiaceae (três) e Marantaceae (sete), num total de 11 espécies. Dentre essas, destacamse as coletas de Heliconia episcopalis Vell., originalmente conhecida no Nordeste apenas para os estados de Alagoas, Bahia e Ceará, e Maranta subterranea J.M.A. Braga, para Bahia (BFG 2015); neste trabalho constituem novos registros para Pernambuco.

De modo geral, as espécies encontradas têm ampla distribuição geográfica na América Central e do Sul, porém Ctenanthe glabra (Körn.) Eichler, Maranta divaricata Roscoe, M. subterranea e Stromanthe porteana Gris. são endêmicas do Brasil, das quais as duas espécies de Maranta são endêmicas da Floresta Atlântica (BFG 2015).

Os representantes de Marantaceae foram coletados em diversos habitats, desde vegetação aberta, como margens de estrada (ex. Stromanthe porteana), a interior de fragmentos (ex. Maranta divaricata), e áreas encharcadas [ex. Ischnosiphon gracilis (Rudge) Körn.]. Costus spiralis (Jacq.) 
Roscoe foi observado em bordas de mata e sítios ripários, e as Heliconiaceae tanto em bordas e clareiras (ex. Heliconia psittacorum L.f.) quanto no interior próximo a nascentes (ex. Heliconia spathocircinata Aristeg.).

Os resultados demonstram um número superior de espécies de Zingiberales na USJ em comparação a outros inventários em florestas de terras baixas na região, como Amazonas \& Barbosa (2011), Dantas et al. (2010), Rodal et al. (2005) (uma espécie cada), Pereira \& Alves (2007) (duas espécies), Nascimento et al. (2012) (três espécies) e Souza et al. (2009) (quatro espécies). O número de espécies inventariadas na USJ é superado somente por áreas montanas do sul da Bahia, com 16 espécies (Coelho \& Amorim 2014).

Os dados reforçam a importância da área para conservação da biodiversidade da Floresta Atlântica pernambucana, onde o número de espécies encontrado representa $50 \%$ das espécies de Costaceae encontradas no estado, $100 \%$ de Heliconiaceae e $40 \%$ das Marantaceae. O estudo agrega valor aos fragmentos da USJ que se destacam como uma importante área a ser preservada em razão da riqueza de espécies dos grupos já estudados (Alves et al. 2013).

\section{Chave para identificação das famílias e espécies de Zingiberales da Usina São José}

1. Pecíolo com pulvino; flores assimétricas, estame único com apenas uma teca fértil.

2. Ervas caulescentes, caule ramificado.

3. Folhas com ápice atenuado a acuminado; címula braquiblástica, pedúnculo $\leq 1 \mathrm{~mm}$ compr.; bractéola presente...................................................................3.3. Ischnosiphon gracilis

3'. Folhas com ápice agudo; címula dolicoblástica, pedúnculo $\geq 2 \mathrm{~mm}$ compr.; bractéola ausente.

4. Folhas minutamente ciliadas, bainha tomentosa, lígula presente; bráctea principal naviculada; espatas róseas 3.7. Stromanthe porteana

4'. Folhas não ciliadas, bainha espaçadamente serícea, lígula ausente; bráctea principal frondosa; espatas verdes. 3.4. Maranta divaricata

2'. Ervas rosuladas ou zingiberoides, com caule reduzido ou pseudocaule não ramificado.

5. Ervas zingiberoides; folhas sésseis ou curtamente pecioladas, pecíolo $\leq 1 \mathrm{~mm}$ compr.; címulas dolicoblásticas, pedúnculo da címula $\geq 2 \mathrm{~cm}$ compr. ...................3.5. Maranta subterranea

5'. Ervas rosuladas; folhas pecioladas, pecíolo $\geq 7 \mathrm{~cm}$ compr.; címulas braquiblásticas, pedúnculo da címula $\leq 6 \mathrm{~mm}$ compr.

6. Pecíolo e pulvino separados por um anel piloso; folhas com margens minutamente ciliadas; profilo da florescência unicarenado ou carena ausente; címulas com 1 flor..... 3.6. Monotagma plurispicatum

6'. Anel piloso no ápice do pecíolo ausente; folhas com margens não ciliadas; profilo da florescência bicarenado; címulas com duas flores.

7. Lâmina foliar elíptica a lanceolada, pecíolo glabro; inflorescência originando-se diretamente do rizoma, espata pubérula, ápice atenuado, acuminado a agudo; interfilo presente, flores amarelas 3.2. Goeppertia sp.

7'. Lâmina foliar oblonga a oblongo-lanceoladas, pecíolo serício; sinflorescência axilar, espata glabra, ápice arredondado; interfilo ausente, flores alvas translúcidas a azuladas 3.1. Ctenanthe glabra

1'. Pecíolo sem pulvino; flores zigomorfas, estames 1 ou 5, com 2 tecas férteis.

8. Folhas alterno-espiraladas, bainha fechada, lígula presente; flores com 1 estame fértil, estaminódios petaloides fundidos formando um labelo; fruto com cálice persistente........... 1.1. Costus spiralis

8'. Folhas alterno-dísticas, bainha aberta, lígula ausente; flores com 5 estames férteis, 1 estaminódio reduzido; fruto com cálice caduco.

9. Pedúnculo da inflorescência menor que a raque ( $\leq 12 \mathrm{~cm}$ compr.); espatas com ápice recurvo 2.3. Heliconia spathocircinata

9'. Pedúnculo da inflorescência maior que a raque ( $\geq 37 \mathrm{~cm}$ compr.); espatas com ápice reto.

10. Espatas sobrepostas, recobrindo totalmente a raque, pubescentes; bractéola oblongolanceolada, serícea; perianto parcialmente encoberto pela espata

10’. Espatas não sobrepostas, raque totalmente exposta, glabras; bractéola deltoide, glabra; perianto exposto 2.2. Heliconia psittacorum 


\section{Costaceae}

1.1. Costus spiralis (Jacq.) Roscoe, Trans. Linn. Soc. London 8: 350. 1807.

Fig. 1a-c

Ervas caulescentes, caule não ramificado.

Folhas alterno-espiraladas; bainha 1,5-5 cm compr., glabra, fechada; pecíolo 3-8 mm compr., estrigoso; lígula presente; pulvino ausente; lâmina 7-26 × 4,3-6,7 cm, elíptica a oblanceolada, margem não ciliada, ápice agudo, base subcordada, face abaxial e nervura central pilosa. Inflorescência terminal, séssil; raque 4-8 cm compr.; brácteas 2-4 × 1,5-2 $\mathrm{cm}$, vermelhas, largo-elípticas a ovadas, glabras, ápice agudo a obtuso; bractéola 1,8-2,6 × 0,6-0,9 $\mathrm{cm}$, rósea, oblonga, ápice agudo. Flores zigomorfas, 1 por bráctea, sésseis, vermelhas a róseas; sépalas 0,8-1,4 cm compr., conadas formando um tubo, vermelhas, ápice arredondado, lobos $2-3 \mathrm{~mm}$ compr., espaçadamente pilosas; pétalas 3-3,5 × 1,2-2 cm, vermelhas a róseas, elípticas a largo-elípticas, ápice arredondado, glabras, adnatas na base com o androceu formando um tubo; tubo da corola 1-1,5 cm compr.; labelo estaminodial petaloide 4-4,5 × 2,5-3 cm, vermelho a róseo, obdeltoide, glabro, ápice truncado; estame fértil 1, 4-5 cm compr., róseo com mácula amarela; 2 tecas férteis; estigma 1,5-2 mm compr.; ovário 0,6-1 cm compr., elipsoide, espaçadamente piloso. Frutos $0,7 \times 1,5 \mathrm{~cm}$ compr., elípticos, glabros, cálice persistente.

Material examinado selecionado: Mata da Usina, 24.IV.2003, fl. e fr., A. Melquíades \& G.J. Bezerra 158 (PEUFR); Mata de Macacos, VII.2014, fl.e fr., N.K. Luna et al. 52 (UFP); Mata de Pezinho, 15.V.2009, fl. e fr., T.A. Pontes 177 (UFP); Mata de Piedade, 21.XI.2013, fl.e fr., N.K. Luna et al. 19 (UFP); 21.I.2014, fl. e fr., N.K. Luna et al. 23 (RB, UFP).

Costus spiralis está distribuída na América do Sul tropical (Maas 1972; Govaerts et al. 2014), ocorrendo em todas as regiões do Brasil (BFG 2015). Ocasional, ocorre em bordas e sítios ripários. Único representante da família na área, é reconhecida por possuir filotaxia alterno-espiralada, lígula, estaminódios petaloides fundidos formando o labelo e frutos com cálice persistente.

\section{Heliconiaceae}

Ervas musoides. Folhas alterno-dísticas, bainha aberta, pecíolo com lígula ausente, pulvino ausente, lâmina oblonga. Inflorescência terminal, espatas cimbiformes, sobrepostas ou não. Flores 1-10 por espata, zigomorfas, sépalas e pétalas adnatas na base ao androceu formando um tubo; estames férteis-5, anteras com 2 tecas férteis, estaminódio-1; ovário glabro. Frutos globosos, glabros, cálice caduco.
2.1. Heliconia episcopalis Vell., Fl. Flumin.: 107. 1827.

Fig. 1d-e

Ervas musoides. Folhas, bainha 41-112,5 cm compr., margem vilosa no ápice; pecíolo 32-57 cm compr., glabro; lâmina 26-133,5 × 12-28 cm, oblonga, margem não ciliada, ápice acuminado, base assimétrica, glabra. Inflorescência, pedúnculo 41,5-44 cm compr., porção superior velutina, base pilosa; raque 7-9 cm comp., reta, pubescente; espatas sobrepostas, recobrindo totalmente a raque, 3-6 $\times 2-2,6 \mathrm{~cm}$, vermelho-alaranjado, ápice amarelo, pubescentes, ápice agudo-reto; bractéola 3-4,5 $\times$ 0,3-0,8 cm, creme-amarronzada, oblongo-lanceolada, serícea, ápice agudo, viloso. Flores 1-3 por espata, perianto parcialmente encoberto, alvo-amareladas; sépala dorsal 3,5-4,2 × 0,3-0,4 $\mathrm{cm}$ acima do tubo, lanceoladas, canaliculadas, retas ou ligeiramente curvas, alvo-amareladas, ápice agudo, viloso, nervura central lanosa; ventrais 3,5-4 × 0,2-0,25 cm acima do tubo, lanceoladas, alvo-amareladas, ápice agudo, viloso, nervura central lanosa; pétalas 3,5-4,2 $\times 0,15-$ $0,2 \mathrm{~cm}$ acima do tubo, alvo-amareladas, oblongolanceoladas, glabras, ápice agudo; tubo 3-4 mm compr.; estames férteis 4,3-4,4 cm compr., alvos; antera $1 \mathrm{~cm}$ compr., estaminódio $1-1,5 \mathrm{~cm}$ compr., alvo; estilete 4,1-4,5 cm compr.; ovário ca. $3 \mathrm{~mm}$ compr., obovoide, glabro. Frutos 6-7 mm compr., globosos, glabros.

Material examinado: Mata próximo a Macacos, 12.II.2014, fl. e fr., N.K. Luna \& J.R. Maciel 38 (HUEFS, RB, SP, UFP).

Material adicional: BRASIL. Pernambuco: Goiana, Mata da Usina Santa Tereza, 23.V.1977, fl. e fr., I. Pontual 77 (PEUFR).

Heliconia episcopalis está distribuída na América do Sul tropical e no Brasil ocorre nas regiões Centro-Oeste, Nordeste, Norte, e Sudeste (Andersson 1992; BFG 2015; Govaerts \& Kress 2014), sendo um novo registro para Pernambuco. Rara, restrita às áreas de tabuleiros. Pode ser confundida vegetativamente na área com H. psittacorum, da qual se diferencia por possuir espatas adaxialmente pubescentes e sobrepostas, que cobrem parcialmente o perianto.

2.2. Heliconia psittacorum L.f., Suppl. Pl.: 158 . 1782. Fig. 1f-g

Ervas musoides. Folhas, bainha 23,5-117,5 cm compr., glabra; pecíolo 1,7-37,5 cm compr., glabro; lâmina 21-68,5 × 4-11 cm, oblonga, margem não ciliada, ápice acuminado, base assimétrica, glabra. Inflorescência, pedúnculo 37-72,5 cm compr., glabro; raque 9,5-18 cm compr., reta, glabra, totalmente exposta; espatas não sobrepostas, 2,5-24 × 0,6-1,9 

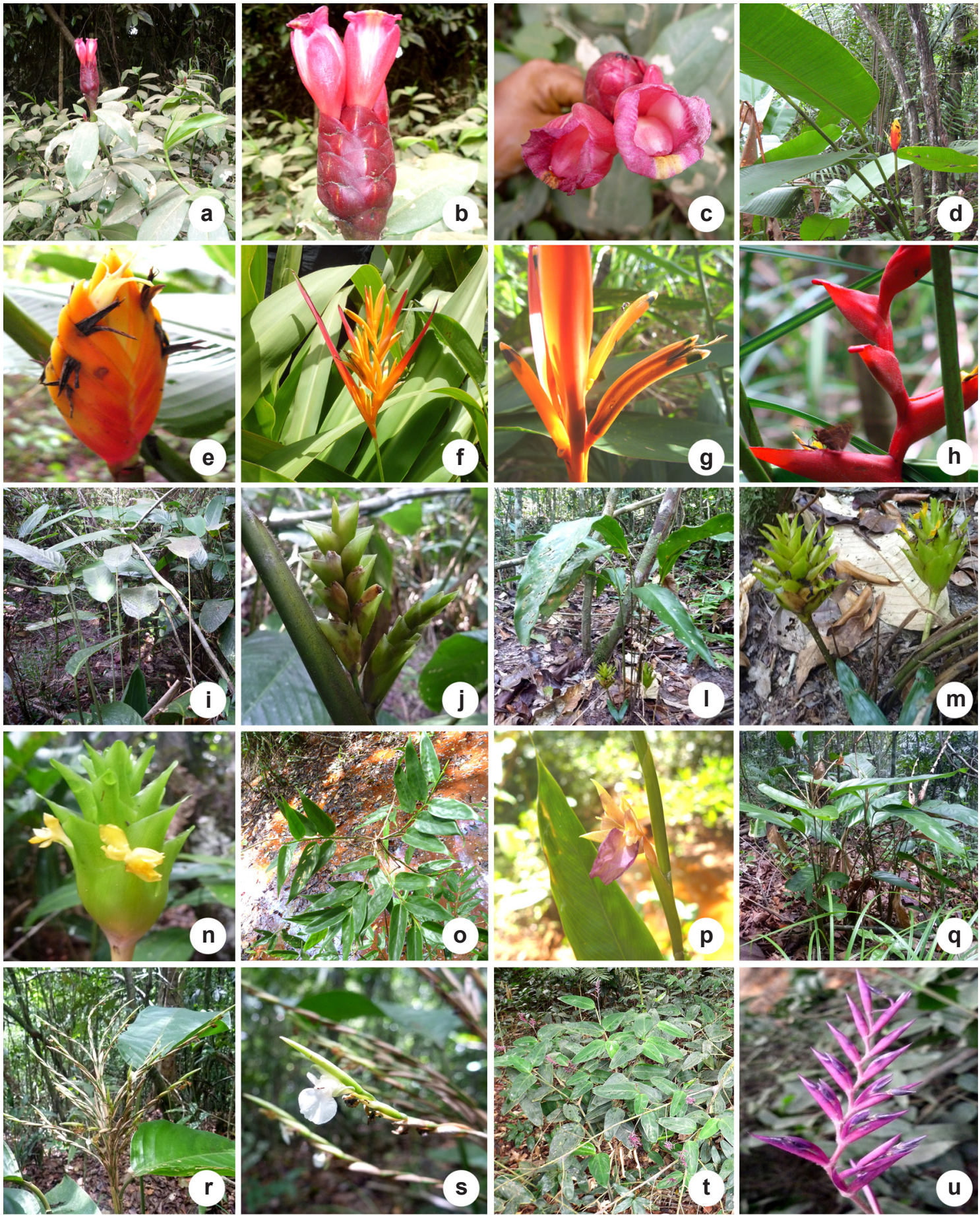

Figura 1 - a-c. Costus spiralis. d-e. Heliconia episcopalis. f-g. Heliconia psittacorum. h. Heliconia spathocircinata. $\mathrm{i}$-j. Ctenanthe glabra. 1-n. Goeppertia sp. o-p. Ischnosiphon gracilis. q-s. Monotagma plurispicatum. t-u. Stromanthe porteana.

Figure 1 - a-c. Costus spiralis. d-e. Heliconia episcopalis. f-g. Heliconia psittacorum. h. Heliconia spathocircinata. i-j. Ctenanthe glabra. 1-n. Goeppertia sp. o-p. Ischnosiphon gracilis. q-s. Monotagma plurispicatum. t-u. Stromanthe porteana. 
$\mathrm{cm}$, laranjas com ápice vermelho, glabras, ápice agudo reto, lustroso; bractéola 1,7-2,5 × 0,3-0,6 $\mathrm{cm}$, alaranjada, deltoide, glabra, ápice agudo. Flores 5-10 por espata, perianto exposto, laranja com ápice verde; sépala dorsal 4,1-4,4 × 0,9-1 $\mathrm{cm}$ acima do tubo, lanceoladas, canaliculada, reta ou ligeiramente curva, laranja com uma linha horizontal verde no ápice, glabra, ápice agudo; ventrais $3,7-4,4 \times 0,2-0,3 \mathrm{~cm}$ acima do tubo, lanceoladas, laranja com uma linha horizontal verde no ápice, glabra, ápice agudo; pétalas $3,7-4,6 \times 0,5-1,2 \mathrm{~cm}$ acima do tubo, laranja com ápice verde, oblongas, glabras, ápice agudo; tubo 3-7 mm compr.; estames férteis 2,8-3 cm compr., alvos com ápice preto amarelado; antera 1-1,3 cm compr.; estaminódio $0,7-1 \mathrm{~cm}$ compr., alvo; estilete $3,2-5 \mathrm{~cm}$ compr.; ovário $3-8 \mathrm{~mm}$, obovoide-triqueto, glabro. Frutos 8-11 mm compr., globosos, glabros.

Material examinado selecionado: Mata das Vespas, 29.XI.2007, fl., A. Melo \& N. Albuquerque 192 (UFP); Mata de Macacos, 3.V.2002, fl. e fr., A. Oliveira \& A.G. Silva 2 (PEUFR); Mata de Piedade, 24.IX.1971, fl., C.M. Costa Soares 138 (PEUFR); 16.IV.2014, fl., N.K. Luna et al. 40 (BHCB, CEPEC, HUEFS, JPB, R, RB, SP, UFP); Mata de Zambana, 29.XI.2007, fr., A. Melo \& N. Albuquerque 189 (UFP).

Heliconia psittacorum está distribuída nas Antilhas, Colômbia, Guiana, Guiana Francesa, Panamá, Suriname, Venezuela, e nas regiões Centro-Oeste, Nordeste, Norte, e Sudeste do Brasil(Andersson 1985; BFG 2015; Govaerts \& Kress 2014). Comum, ocorre em bordas, declives e sítios ripários. Vegetativamente pode ser confundida com H. episcopalis, porém se diferencia pelas espatas glabras não sobrepostas e perianto exposto.

2.3. Heliconia spathocircinata Aristeg., Bol. Soc. Venez. Ci. Nat. 22: 18. 1961.

Fig. $1 \mathrm{~h}$

Ervas musoides. Folhas, bainha ca. $80 \mathrm{~cm}$ compr., espaçadamente pubescente; pecíolo 19-56 cm compr., glabro; lâmina 58,5-77,5 × 17-29 cm, oblonga, margem não ciliada, ápice acuminado, base assimétrica, glabra. Inflorescência, pedúnculo 8-12 cm compr., glabrescente; raque totalmente exposta, 19-35,5 cm compr., sinuosa, espaçadamente pubescente; espatas não sobrepostas, $5-45 \times$ 1-3 cm, laranja-avermelhadas, espaçadamente pubescentes, ápice agudo recurvo; bractéola 4,5$5,5 \times 0,9-1,8 \mathrm{~cm}$, amarelada, elíptica assimétrica, espaçadamente vilosa, ápice agudo. Flores 7 por espata, perianto parcialmente coberto pela espata, amarela; sépala dorsal 2,9-4,3 × 0,3-0,6 cm acima do tubo, lanceolada a elíptica, canaliculada, reta ou ligeiramente curva, amarelas, viloso, ápice agudo; ventrais $2,5-3,6 \times 0,2-0,4 \mathrm{~cm}$ acima do tubo, lanceoladas a elípticas, amarelas, espaçadamente vilosas, ápice agudo; pétalas $2,8-4,6 \times 0,1-0,2 \mathrm{~cm}$ acima do tubo, amarelas, lanceolada a elíptica, margens velutinas, ápice agudo; tubo 0,5-1 cm compr.; estames férteis $2-4,3 \mathrm{~cm}$ compr., amarelados; antera $0,9-1,3 \mathrm{~cm}$ compr., estaminódio 4-7 mm compr., amarelados; estilete 2,4-4 cm compr.; ovário 3-7 mm compr., obovoide-triqueto, glabro; frutos 7-9 mm compr., globosos, glabros.

Material examinado: Mata de Piedade, 20.XII.2007, fl., A. Alves-Araújo \& D. Araújo 738 (UFP); 20.XII.2007, fl., D. Araújo \& A. Alves-Araújo 551 (UFP).

Material adicional: BRASIL. Pernambuco: Cabo de Santo Agostinho, Reserva Ecológica do Gurjaú, 10.VI.2003, fr., J.A. Siqueira-Filho 1332 (UFP); Jaqueira, Usina Colônia, 24.V.1999, fl. e fr., J.A. Siqueira-Filho \& C.B. Neves 915 (UFP); São Vicente Férrer, Serra do Mascarenhas, 5.V.1999, fr., C. Neves (UFP).

Heliconia spathocircinata ocorre na América do Sul tropical, Panamá, Tobago e Trinidad. No Brasil é citada para as regiões Centro-Oeste, Nordeste, Norte e Sudeste (Andersson 1992; BFG 2015; Govaerts \& Kress 2014). Rara, ocorre em tabuleiros e sítios ripários. É reconhecida na área por possuir o pedúnculo da inflorescência menor que a raque, e pelas espatas com ápice recurvo.

\section{Marantaceae}

Ervas rosuladas, caulescentes ou zingiberoides. Folhas rosuladas ou alternodísticas, bainha aberta, pecíolo com pulvino, lígula ausente ou raramente presente, lâmina oblonga a oblongo-lanceolada, elíptica a lanceolada ou ovada. Sinflorescência axilar, originando-se diretamente do rizoma ou terminal; florescências 1-17 por nó; címulas braquiblástica ou dolicoblásticas. Flores assimétricas, 1-2 por címula, sépalas livres, pétalas adnatas na base ao androceu formando um tubo, estaminódios externos 1-2; estaminódio cuculado-1, estaminódio caloso-1; estame + apêndice com apenas 1 teca fértil, ovário glabro, piloso, pubérulo ou seríceo. Frutos angulosos, elípticos, globosos ou fusiformes, glabros, hirsutos, pilosos ou seríceos, cálice persistente ou caduco.

3.1. Ctenanthe glabra (Körn.) Eichler, Abh. Königl. Akad. Wiss. Berlin: 83. $1884 . \quad$ Fig. 1 i-j Ervas rosuladas, não ramificadas. Folhas rosuladas; bainha $22-59,5 \mathrm{~cm}$ compr., serícea; 
pecíolo 35,5-95,5 cm compr., seríceo; lígula ausente; pulvino glabro; lâmina 11-65,7 × 8,5-14,1 $\mathrm{cm}$, oblonga a oblongo-lanceolada, margem não ciliada, ápice acuminado deslocado lateralmente, base cuneada, glabra. Sinflorescência axilar; pedúnculo 4-27 cm compr., espaçadamente seríceo; bráctea principal 5,5-92 cm compr., verde, naviculada ou frondosa, ápice acuminado, glabro a pubérulo. Florescência 3-4 por nó; profilo da florescência 1,5-7,5 cm compr., naviculado, ápice acuminado, glabro; pedúnculo $1-15,5 \mathrm{~cm}$ compr., espaçadamente piloso; espatas 1,5-2,9 cm compr., verdes lustrosas, ovadas, ápice arredondado, glabras; címulas braquiblásticas; pedúnculo 1-2 $\mathrm{mm}$ comp., glabro; profilo da címula 1-1,2 cm compr., amarelo, oblongo, bicarenado, ápice arredondado a cuspidado, glabro; interfilo ausente; bractéola 1,2-1,7 mm compr., amarela, lanceolada a oblonga, ápice agudo, glabra. Flores, 2 por címula; sépalas 9-11 × 2,5-4 mm, oblongas a lanceoladas, creme, glabra, ápice agudo. Tubo da corola 3-4 mm compr.; lobos 4-9 × 2-4 mm, oblongos, alvos ou azulados, ápice arredondado a retuso; estaminódios externos 2, 7-8,5 mm compr., obovados, alvostranslúcidos a azulados; estaminódio cuculado 1 , 6,5-7 mm compr., oblongo, alvo translúcido a azulado; estaminódio caloso 1, 7,3-8 mm compr., oblongo, alvo translúcido a azulado; estame + apêndice 6-7 × 0,7-1 mm, linear, creme; estilete 6-7 mm compr.; ovário 1,5-2,5 mm compr., elipsoide, glabro. Frutos não vistos.

Material examinado: Mata de Piedade, 10.I.2008, fl., A. Alves-Araújo et al. 791 (UFP); 17.XII.2009, fl., D. Cavalcanti \& J.D. Garcia 35 (UFP); 21.I.2014, fl., N.K. Luna et al. 30 (HUEFS, JPB, RB, SP, UFP).

Ctenanthe glabra é endêmica do Brasil e amplamente distribuída em todas as regiões (BFG 2015; Govaerts \& Kennedy 2014). Ocasional, ocorre em tabuleiros e bordas. Confunde-se vegetativamente na área com Goeppertia sp., mas pode ser diferenciada pelas lâminas oblongas a oblongo-lanceoladas, sinflorescência axilar e flores alvas translúcidas.

\subsection{Goeppertia sp.}

Fig. 1 1-n

Ervas rosuladas não ramificadas. Folhas rosuladas; bainha 15-23 cm compr., espaçadamente serícea; pecíolo 23,5-45,5 cm compr., glabro; lígula ausente; pulvino com linha tomentosa na face abaxial; lâmina $26-35,5 \times 4,5-8 \mathrm{~cm}$, elíptica a lanceolada, margem não ciliada, ápice agudo, base cuneada, glabra. Inflorescência originando-se diretamente do rizoma; pedúnculo
12-18,5 cm compr., pubescente; espatas 3-4,5 cm compr., verdes, ovadas a largo-elípticas, ápice atenuado, acuminado a agudo, pubérulo; címulas braquiblásticas; pedúnculo ca. $1 \mathrm{~mm}$ compr., glabro; profilo da címula 2,3-3,4 cm compr., amarelado, elíptico, bicarenado, ápice agudo, pubérulo; interfilo 1,7-3,2 cm compr., amarelado, elíptico, ápice arredondado a agudo, margens pubérulas; bractéola 1,5-2,1 cm compr., amarelada, elíptica, unicarenada, ápice agudo a arredondado, glabro. Flores 2 por címula; sépalas 13-16,2 × 1,5-3,5 mm, oblongas, esverdeadas, glabras, ápice arredondado; tubo da corola 26-33 $\mathrm{mm}$ compr.; lobos 8-16 × 2-4 mm, oblongos a levemente obovados, amarelos, ápice arredondado a cuspidado; estaminódio externo 1, 10-13 mm compr., obovado, amarelo; estaminódio cuculado 1, 7-9 mm compr., oblongo-obovado, amarelo; estaminódio caloso 1, 6-11 mm compr., obovado, amarelo; estame + apêndice 6-10 × 1-1,8 mm, oblanceolado, ocre; estilete 6-12 mm compr.; ovário 1-2 mm compr., cilíndrico, glabro. Frutos não vistos.

Material examinado: Mata de Piedade, 21.I.2014, fl., N.K. Luna et al 27 (JPB, HUEFS, RB, SP, UFP); 4.III.2010, fl., J.D. García-Gonzales 1462 (UFP).

Goeppertia sp. é morfologicamente relacionada com G. ovata (Nees \& Mart.) Borchs. \& S. Suárez e G. umbrosa (Körn.) Borchs. \& S. Suárez. Mas diferencia-se da primeira pelo pedúnculo mais longo ( $\geq 12 \mathrm{~cm}$ vs. $\leq 9 \mathrm{~cm}$ ), e da segunda pela inflorescência basal, originando-se do rizoma (vs.terminal, originando-se da bainha foliar). Possivelmente trata-se de uma nova espécie para ciência (M. Saka, com. pess.). Rara, ocorre em sítios ripários. Pode ser confundida vegetativamente na área com Ctenanthe glabra, porém diferencia-se pelas folhas elípticas a lanceoladas, inflorescência originando-se diretamente do rizoma e flores amarelas.

3.3. Ischnosiphon gracilis (Rudge) Körn., Bull. Soc. Imp. Nat. Moscou 35(1): 94. 1862.

Fig. 1o-p

Ervas caulescentes, ramificadas. Folhas dísticas; bainha 2-4,9 cm compr., face abaxial apical serícea; pecíolo ausente, se presente, ca. $3 \mathrm{~cm}$ compr., glabro; lígula ausente; pulvino com face adaxial pubescente; lâmina 4-11,5 × 1,4-4,5 cm compr., ovada a lanceolada, margem não ciliada, ápice acuminado a atenuado, base arredondada a obtusa, face adaxial com ápice e nervura central pubescente, face abaxial pubérula. 
Inflorescência simples, terminal. Florescência 1 por nó, profilo da florescência ausente; bráctea principal 2-12,5 cm compr., verde, oblonga ou frondosa, ápice agudo a cuspidado, face adaxial com metade superior pubérula, face abaxial com metade superior serícea; pedúnculo $1,5-4 \mathrm{~cm}$ compr., glabro; espatas 2-3 cm compr., verdes com ápice amarelo, oblongas, ápice agudo a cuspidado, metade superior pubérula; címulas braquiblásticas; pedúnculo $0,5-1 \mathrm{~mm}$ compr., glabro; profilo da címula 2-2,3 cm compr., creme amarronzado, estreito-elíptico a oblongo, bicarenado, ápice agudo, ápice e carenas pubescentes; interfilo ausente; bractéola 2,3-2,8 cm compr., amarelada com ápice amarronzado, linear, ápice arredondado a agudo, glabra. Flores 2 por címula; sépalas $17-20 \times 1-1,8$ $\mathrm{mm}$, lineares, amareladas, seríceas, ápice agudo. Tubo da corola 25-26 mm compr.; lobos 10-13 $\times$ 3-4 mm, oblongos, ápice agudo, amarelados, face adaxial hirsuta; estaminódio externo 1, 15-21 mm compr.,obovado, lilás; estaminódio cuculado 1,7-8 $\mathrm{mm}$ compr., oblongo, alvo; estaminódio caloso 1 , ca. $8 \mathrm{~mm}$ compr., ovado, alvo; estame + apêndice 7-8 $\times 1-1,2 \mathrm{~mm}$, linear, amarelado; estilete 6-7 mm compr.; ovário 2,5-3,2 mm compr., levemente estreito-obtriangular, metade superior pubérula. Frutos 2,5-3 cm compr., elípticos, hirsutos, cálice persistente.

Material examinado selecionado: Mata de Chave, 22.XII.2014, fl., N.K. Luna et al. 72 (UFP), Mata de Macacos, 9.IV.2014, fl., N.K. Luna et al. 45 (UFP); Mata de Piedade, 21.I.2014, fl. e fr., N.K. Luna et al. 25 (BHCB, CEPEC, HUEFS, JPB, R, RB, SP, UFP).

Ischnosiphon gracilis ocorre no Equador, Guiana Francesa, Peru, Suriname eVenezuela; no Brasil ocorre nas regiões Centro-Oeste, Nordeste, Norte, e Sudeste (Andersson 1977; BFG 2015; Govaerts \& Kennedy 2014). Ocasional, ocorre em tabuleiro e sítios ripários. Na área diferencia-se de outras espécies pelo crescimento caulescente e ramificado, como em Stromanthe porteana e Maranta divaricata; entretanto, possui folhas com ápice atenuado a acuminado, címulas braquiblásticas e bractéola presente.

3.4. Maranta divaricata Roscoe, Monandr. Pl. Scitam.: t. 27. 1828.

Fig. 2a-c

Ervas caulescentes, ramificadas. Folhas dísticas; bainha 3,5-8,5 cm compr., espaçadamente serícea; pecíolo ausente ou presente, ca. $1 \mathrm{~mm}$ compr., espaçadamente seríceo; lígula ausente; pulvino piloso; lâmina 8,6-16 × 1-3,9 cm, ovada, margem não ciliada, ápice agudo, base obtusa a arredondada, nervura central puberulenta. Sinflorescência terminal; pedúnculo 3,5-4,6 $\mathrm{cm}$ compr., espaçadamente pubescente; bráctea principal 3-15,5 cm compr., verde, frondosa, ápice agudo. Florescência 2 por nó; profilo da florescência 2,4-3,9 cm compr., amarelado, oblongo, bicarenado, ápice agudo, glabro; pedúnculo 4,7-7,7 cm compr., pubescente; espatas 3-3,8 cm compr., verdes, oblanceoladas, ápice agudo, espaçadamente pubescentes; címulas dolicoblásticas; pedúnculo 1,5-3,5 cm compr., espaçadamente pubescente; profilo da címula 2-2,6 cm compr., amarelado, linear, unicarenado, ápice agudo, glabro; interfilo ausente; bractéola ausente. Flores 2 por címula; sépalas $10-12 \times 0,9-1,5 \mathrm{~mm}$, oblanceoladas, verdes, glabras, ápice agudo. Tubo da corola 11$13 \mathrm{~mm}$ compr.; lobos 7-8 $\times 1-1,8 \mathrm{~mm}$, oblongos, alvos, ápice agudo; estaminódios externos 2, 7-8 mm compr., obovados, alvos; estaminódio cuculado 1, 6-7 mm compr., oblanceolado, alvo; estaminódio caloso 1, 8-8,5 mm compr., obovado, alvo; estame + apêndice 5-8 $\times 1 \mathrm{~mm}$, obovado, alvo, 1 teca fértil; estilete 12-17 mm compr.; ovário 1,5-1,8 mm compr., anguloso, piloso. Frutos $0,7-1 \mathrm{~cm}$ compr., angulosos, pilosos, cálice persistente.

Material examinado: Mata de Macacos, 4.VII.2014, fl. e fr., N.K. Luna et al. 51 (HUEFS, JPB, RB, SP, UFP); Mata de Zambana, 14.II.2008, fl. e fr., A. Alves-Araújo \& J.S. Marques 835 (UFP).

Material adicional: BRASIL. Pernambuco: Goiana, Capoeira, Restinga de Atapus, X.1969, fl., G. Mariz 496 (UFP); São Lourenço da Mata, Mata do Toró, 23.IX.1969, fl., G. Mariz 457 (UFP).

Maranta divaricata é endêmica da Floresta Atlântica do Brasil e registrada para as regiões Nordeste, Sudeste e Sul (Andersson 1986; BFG 2015; Govaerts \& Kennedy 2014). Rara, ocorre na borda da mata. Pode ser diferenciada de M. subterranea pelo hábito caulescente e ramificado.

\subsection{Maranta subterranea J.M.A. Braga, Eugeniana} 25: 33. 2001.

Fig. 2d-f

Ervas zingiberoides, não ramificadas. Folhas dísticas; bainha 1,5-16,5 cm compr., serícea; pecíolo ausente ou presente, ca. $1 \mathrm{~mm}$ compr., glabro; lígula ausente; pulvino com face adaxial tomentosa, abaxial glabra; lâmina 4,5-18,3 × 1,9-4,4 cm, oblonga a lanceolada, margem não ciliada, ápice agudo, base cuneada, glabra. Sinflorescência terminal e/ou originando-se diretamente do rizoma; pedúnculo 2,9-6 cm compr., espaçadamente pubescente; bráctea principal $12-19 \mathrm{~cm}$ compr., verde, frondosa, ápice agudo, glabra. Florescência 1-3 por nó; profilo 
da florescência 2,8-4,8 cm compr., amarelado, linear a lanceolado, bicarenado, ápice mucronado, glabro; pedúnculo 4-7,5 cm compr., espaçadamente pubescente; espatas 2,9-5,5 cm compr., marromesverdeadas, oblanceoladas a lanceoladas, ápice cuneado a agudo, margens pubérulas; címulas dolicoblásticas; pedúnculo 2-2,8 cm compr., glabrescente; profilo da címula 1,5-2,1 cm compr., creme, oblongo, bicarenado, ápice cuspidado, glabro; interfilo ausente; bractéola ausente. Flores 1 por címula; sépalas $10,5-13 \times 1,5-3 \mathrm{~mm}$, lanceoladas, amarelas esverdeadas, glabras, ápice

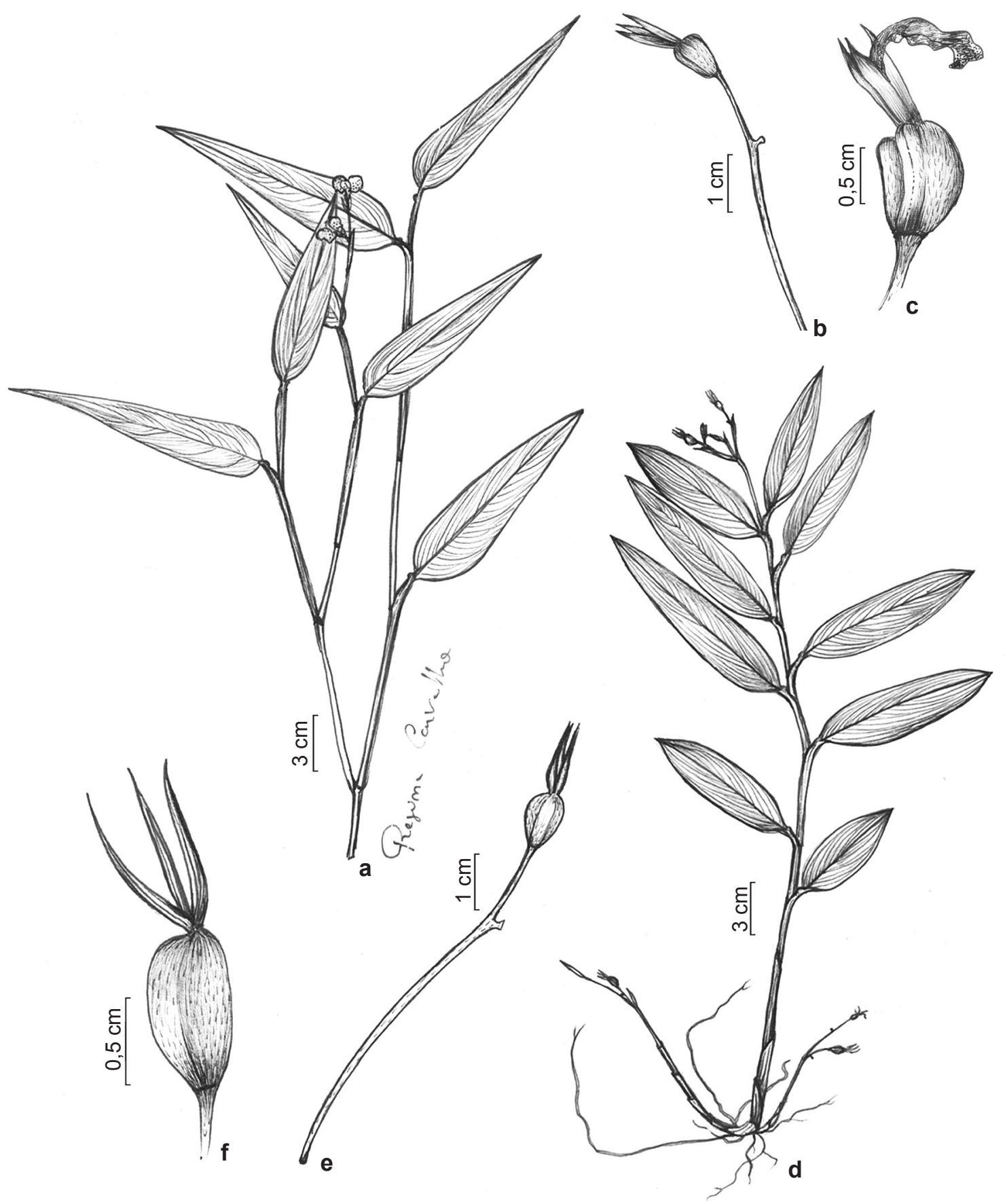

Figura 2 - a-c. Maranta divaricata - a. hábito; b. címula; c. fruto. d-f. Maranta subterranea - d. hábito; e. címula; f. fruto. Figure 2 - a-c. Maranta divaricata - a. habit; b. cymule; c. fruit. d-f. Maranta subterranea - d. habit; e. cymule; f. fruit. 
agudo. Tubo da corola 5-6 mm compr.; lobos 10-13 $\times 2,2-3 \mathrm{~mm}$, oblongos, alvos a translúcidos, ápice agudo; estaminódios externos 2, 9-12 mm compr., obovados, alvos a translúcidos, estaminódio cuculado 1, 7-8 mm compr., oblongo, alvo a translúcido; estaminódio caloso 1, 9-13 mm compr., oblongo, alvo a translúcido; estame + apêndice 9-10 × 3-4 $\mathrm{mm}$, obovado, amarelado; estilete $10-12 \mathrm{~mm}$ compr.; ovário ca. $3 \mathrm{~mm}$ compr., cilíndrico, esverdeado, seríceo. Frutos 1-1,2 cm compr., angulosos, seríceos, cálice persistente.

Material examinado: Mata de Piedade, 21.11.2013, fl. e fr., N.K. Luna \& E. Pessoa 20 (CEPEC, HUEFS, JPB, RB, SP, UFP).

Material adicional: BRASIL. Espírito Santo: Linhares, Reserva da Companhia do Vale do Rio Doce, 20.II.1986, fl. e fr., L. Andersson \& M. Hagberg (CEPEC).

Maranta subterranea é endêmica da Floresta Atlântica do Brasil, ocorrendo nas regiões Nordeste (Bahia) e Sudeste (Espírito Santo e Rio de Janeiro) (BFG 2015; Govaerts \& Kennedy 2014). É um novo registro para o Estado de Pernambuco e apresenta sua área de distribuição ao norte do estado. Rara, ocorre em tabuleiros. Pode ser diferenciada de $M$. divaricata pelo hábito zingiberoide com pseudocaule não ramificado e sinflorescência terminal e/ou originandose diretamente do rizoma.

3.6. Monotagma plurispicatum (Körn.) K. Schum., Pflanzenr. IV(48): 169. $1902 . \quad$ Fig. 1q-s

Ervas rosuladas, não ramificadas. Folhas rosuladas; bainha 17-34,5 cm compr., serícea; pecíolo 7-30 cm compr., pubescente; lígula ausente; pulvino com face adaxial puberulenta, face abaxial glabra, um anel piloso no limite entre o pecíolo e pulvino; lâmina $20,5-44,5 \times 5,8-17 \mathrm{~cm}$, lanceolada a ovada, margem minutamente ciliada, ápice agudo a acuminado, assimétrico, base obtusa a arredondada, nervura central da face adaxial tomentosa e face abaxial glabrescente. Sinflorescência axilar; pedúnculo 1,9$8,9 \mathrm{~cm}$ compr., pubescente; bráctea principal 2-5 cm compr., amarelada, falcada, ápice agudo, seríceo. Florescência 4-17 por nó; profilo 1,2-1,5 cm compr., amarelado, falcado, unicarenado ou sem carena, ápice arredondado, seríceo; pedúnculo 1,8-2,8 cm compr., seríceo; espatas 1,2-2,2 cm compr., verdes, oblongas, incanas, ápice agudo; címulas braquiblásticas; pedúnculo 1-6 mm compr., glabro; profilo da címula 6-12 mm compr., amarelado a amarronzado, oblongo, ápice arredondado a agudo, glabro, metade superior serícea; interfilo ausente; bractéola ausente. Flores 1 por címula; sépalas 4,5-6,2 × 0,5-1,5 mm compr., lineares, esverdeadas, glabras, ápice arredondado.
Tubo da corola 11-12 mm compr.; lobos 4-6 × 1,8$3,2 \mathrm{~mm}$, oblongos a ovados, alvos, ápice obtuso a cuculado; estaminódio externo 1, 7,2-8 mm compr., obovado, alvo; estaminódio cuculado 1, 3-6 mm compr., oblongo a cuculado, alvo; estaminódio caloso 1, 3-6 mm compr., elíptico, alvo; estame + apêndice 3-5 $\times 1-2 \mathrm{~mm}$, linear a oblongo, alvo; estilete 3-7 mm compr.; ovário $1-2,5 \mathrm{~mm}$ compr., cilíndrico, pubérulo na metade superior. Frutos 1,4-1,5 cm compr., fusiformes, ápice piloso, cálice caduco.

Material examinado selecionado: Mata de Macacos, 16.VIII.2007, fl., D. Araújo et al. 436 (UFP); Mata de Piedade, 21.I.2014, fl. e fr., N.K. Luna et al. 24 (HUEFS, JPB, RB, SP, UFP).

Monotagma plurispicatum está distribuída na América Central e Sul e no Brasil ocorre nas regiões Centro-Oeste, Nordeste e Norte (BFG 2015; Govaerts \& Kennedy 2014). Ocasional, ocorre em tabuleiros. É diferenciada das outras espécies na área por possuir um anel piloso no limite entre pecíolo e pulvino e pelas espatas verdes.

3.7. Stromanthe porteana Gris., Ann. Sci. Nat., Bot. 4(9): 185.1858.

Fig. 1t-u

Ervas caulescentes, ramificadas. Folhas dísticas; bainha 6-12 cm compr., tomentosa; sésseis a pecioladas; pecíolo ca. $2 \mathrm{~mm}$ compr., viloso; lígula tomentosa; pulvino com face adaxial vilosa, face abaxial glabra; lâmina $9-23 \times 3,8-8 \mathrm{~cm}$, ovada, margem minutamente ciliada, ápice agudo, base obtusa, face adaxial espaçadamente pilosa e nervura central canaliculada pilosa. Sinflorescência terminal; pedúnculo 4-19,5 cm compr., viloso; bráctea principal 3-7,6 cm compr., rósea, naviculada, vilosa, ápice agudo. Florescência 1-3 por nó; profilo da florescência 2,5-4,8 cm compr., naviculado, ápice agudo, glabro; pedúnculo 3-9,7 cm compr.; espatas 1,5-2,8 cm compr., róseas, oblanceoladas, ápice agudo, face abaxial basalmente pilosa; címulas dolicoblásticas; pedúnculo 2,5-9 $\mathrm{mm}$ compr., piloso; profilo da címula $0,9-1,9 \mathrm{~cm}$ compr., róseo, naviculado, ápice agudo, glabro; interfilo ausente; bractéola ausente. Flores 2 por címula; sépalas 6-8 $\times 3-5 \mathrm{~mm}$, ovadas, lilases, glabras, ápice obtuso a agudo. Tubo da corola 1-3 mm compr.; lobos 5-8 $\times$ 2-4 mm, oblongos, lilases, ápice arredondado a retuso; estaminódios externos 2, 5-6 mm, espatulados, alvos; estaminódio cuculado 1, 6-7 mm compr., oblongo, alvo; estaminódio caloso 1, 6-8 mm compr., elíptico,

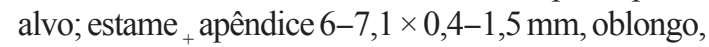
alvo; estilete 6-7,5 mm compr.; ovário 1,6-2 $\mathrm{mm}$, obovoide, seríceo. Frutos 4-9 mm compr., globosos a elipsoides, seríceos, cálice persistente. 
Material examinado selecionado: Mata da Usina São José, 16.X.2002, fl., G.J. Bezerra \& M.J. Silva 45 (UFP); Mata de Macacos, 15.VI.2007, fl. e fr., A. Alves-Araújo et al. 392 (UFP); 4.VII.2014, fl., N.K. Luna et al. 53 (HUEFS, RB, UFP); Mata de Piedade, 21.XI.2013, fl., N.K. Luna et al. 17 (CEPEC, HUEFS, JPB, RB, SP, UFP).

Stromanthe porteana é endêmica do Brasil, ocorrendo nas regiões Nordeste e Sudeste (BFG 2015; Govaerts \& Kennedy 2014). Comum, ocorre em tabuleiros e borda. Na área pode ser confundida com Maranta divaricata, mas se diferencia por possuir lâminas minutamente ciliadas, lígula presente, bráctea principal naviculada e espatas róseas.

\section{Agradecimentos}

À Usina São José, o apoio logístico para as coletas. Ao CNPq e National Science Foundation, o financiamento das viagens a campo. À Regina Carvalho, as ilustrações. E aos curadores dos herbários visitados.

\section{Referências}

Almeida, E.R. 1993. Plantas medicinais brasileiras conhecimentos populares e científicos. Hemus Editora, São Paulo. 341p.

Alonso, A.M. \& Sousa-Silva, J.C. 2009. Heliconia angusta Vell.: Caracterização de uma planta ornamental para cultivo no Cerrado. Embrapa Cerrado, Planaltina. 24p.

Alves, M.; Alves-Araújo, A.; Amorim, B.; Araújo, A.; Araújo, D.; Araujo, M.F.; Buril, M.T.; Costa-Lima, J.; Garcia-Gonzalez, J.; Gomes-Costa, G.; Melo, A.; Novaes, J.; Oliveira, S.; Pessoa, E.; Pontes, T. \& Rodrigues, J. 2013. Inventário de Angiospermas dos fragmentos de Mata Atlântica da Usina São José, Igarassu, Pernambuco. In: Buril, M.T.; Melo, A.; Alves-Araújo, A. \& Alves, M. (eds.). Plantas da Mata Atlântica: Guia de árvores e arbustos da Usina São José (Pernambuco). Ed. Livro Rápido, Recife. Pp. 133-158.

Amazonas, N.T. \& Barbosa, M.R.V. 2011. Levantamento florístico das angiospermas em um remanescente de Floresta Atlântica Estacional na Microbacia Hidrográfica do Rio Timbó, João Pessoa, Paraíba. Revista Nordestina de Biologia 20: 67-78.

Andersson, L. 1977. The genus Ischnosiphon (Marantaceae). Opera Botanica 43: 1-107.

Andersson, L. 1981a. The Neotropical genera of Marantaceae. Circumscription and relationships. Nordic Journal of Botany 1: 218-245.

Andersson, L. 1981b. Revision of Heliconia sect. Heliconia (Musaceae). Nordic Journal of Botany 1: 759-784.

Andersson, L. 1985. Revision of Heliconia subgen. Stenochlamys (Musaceae-Heliconioideae). Opera Botanica 82: 1-123.
Andersson, L. 1986. Revision of Maranta subg. Maranta (Marantaceae). Nordic Journal of Botany 6: 729-756.

Andersson, L. 1992. Revision of Heliconia subgen. Taeniostrobus and subgen. Heliconia (MusaceaeHeliconioideae). Opera Botanica 111: 1-98.

Andersson, L. 1998a. Heliconiaceae. In: Kubitzi, K.; Huber, H.; Rudall, P.J.; Stevens, P.S. \& Stutzel, T. (eds.). Flowering plants: Monocotyledons. Alismatanae and Commeliananae (except Gramineae). Vol. 4. Springer-Verlag, BerlinHeidelberg. Pp. 226-230.

Andersson, L. 1998b. Marantaceae. In: Kubitzi, K.; Huber, H.; Rudall, P.J.; Stevens, P.S. \& Stutzel, T. (eds.). Flowering plants: Monocotyledons. Alismatanae and Commeliananae (except Gramineae). Vol. 4. Springer-Verlag, Berlin-Heidelberg. Pp. 278-293.

Andersson, L. 1998c. Musaceae. In: Kubitzi, K.; Huber, H.; Rudall, P.J.; Stevens, P.S. \& Stutzel, T. (eds.). Flowering plants: Monocotyledons. Alismatanae and Commeliananae (except Gramineae). Vol. 4. Springer-Verlag, Berlin-Heidelberg. Pp. 296-301.

Andersson, L. 1998d. Strelitziaceae. In: Kubitzi, K.; Huber, H.; Rudall, P.J.; Stevens, P.S. \& Stutzel, T. (eds.). Flowering plants: Monocotyledons. Alismatanae and Commeliananae (except Gramineae). Vol. 4. Springer-Verlag, BerlinHeidelberg. Pp. 451-455.

APG III. 2009. An update of the Angiosperm Phylogeny Group classification for the orders and families of flowering plants: APG III. Botanical Journal of the Linnean Society 161: 105-121.

Araújo, D. \& Alves, M. 2013. Flora da Usina São José, Igarassu, Pernambuco: Passifloraceae. Rodriguesia 64: $247-254$

BFG. 2015. Growing knowledge: an overview of Seed Plant diversity in Brazil. Rodriguésia 66: 1085-1113.

Coelho, M.M. \& Amorim, A.M. 2014. Floristic composition of the Montane Forest in the AlmadinaBarro Preto axis, Southern Bahia, Brazil. Biota Neotropica 14: 1-41.

Dahlgren, R.M.T.; Clifford, H.T. \& Yeo, P.F. 1985. The Families of the Monocotyledons. Springer-Verlag, Berlin. 520p.

Dantas, T.V.P.; Nascimento-Júnior, J.E.; Ribeiro, A.S. \& Prata, A.P.N. 2010. Florística e estrutura da vegetação arbustivo-arbórea das Areias Brancas do Parque Nacional Serra de Itabaiana/Sergipe, Brasil. Revista Brasileira de Botânica 33: 575-588.

Endress, P.K. 1994. Diversity and evolutionary biology of tropical flowers. Cambridge University Press, Cambridge. 551p.

Galindo-Leal, C. \& Câmara, I.G. 2003. Atlantic forest hot spots status: an overview. In: Galindo-Leal, C. \& Câmara, I.G. (eds.). The Atlantic Forest of South America: biodiversity status, Threats, and Outlook. CABS \& Island Press, Washington. Pp. 3-11. 
Gonçalves, E. \& Lorenzi, H. 2007. Morfologia vegetal - organografia e dicionário Ilustrado de morfologia das plantas vasculares. Instituto Plantarum, São Paulo. 415p.

Govaerts, R. \& Kennedy, H. 2014. Wold checklist of Marantaceae. The board of trustees of the Royal Botanic Gardens, Kew. Disponível em <https:// apps.Kew.org/wcsp/>. Acesso em 14 outubro 2014.

Govaerts, R. \& Kress, J. 2014. Wold Checklist of Heliconiaceae. The board of trustees of the Royal Botanic Gardens, Kew. Disponível em <https:// apps.Kew.org/wcsp/>. Acesso em 14 outubro 2014.

Govaerts, R.; Maas, H.K. \& Maas, P.K. 2014. Wold checklist of Costaceae. The board of trustees of the Royal Botanic Gardens, Kew. Disponível em $<$ https://apps.Kew.org/wcsp/>. Acesso em 14 outubro 2014.

Harris, J. \& Harris, M. 2001. Plant identification terminology - an illustrated glossary. $2^{\text {nd }}$ ed. Spring Lake Publishing, Payson. 260p.

IBGE. 2012. Manual técnico da vegetação brasileira: sistema fitogeográfico, inventário das formações florestais e campestres, técnicas e manejo de coleções botânicas, procedimentos para mapeamentos. $2^{\mathrm{a}} \mathrm{ed}$. IBGE-Instituto Brasileiro de Geografia e Estatística, Rio de Janeiro. 275p.

Kennedy, H. 2000. Diversification in pollination mechanisms in the Marantaceae. In: K.L. Wilson \& D.A. Morrison (eds.). Monocots, systematics and evolution. Csiro, Melbourne. Pp. 335-343.

Kress, W.J. 1990. The Phylogeny and Classification of the Zingiberales. Annals of the Missouri Botanical Garden 77: 698-721.

Kubitzki, K. 1998. Cannaceae. In: Kubitzi, K.; Huber, H.; Rudall, P.J.; Stevens, P.S. \& Stutzel, T. (eds.). Flowering plants: Monocotyledons. Alismatanae and Commeliananae (except Gramineae). Vol. 4. Springer-Verlag, Berlin-Heidelberg. Pp. 103-106.

Larsen, K. 1998a. Costaceae. In: Kubitzi, K.; Huber, H.; Rudall, P.J.; Stevens, P.S. \& Stutzel, T. (eds.). Flowering plants: Monocotyledons. Alismatanae and Commeliananae (except Gramineae). Vol. 4. Springer-Verlag, Berlin-Heidelberg. Pp. 128-132.

Larsen, K. 1998b. Lowiaceae. In: Kubitzi, K.; Huber, H.; Rudall, P.J.; Stevens, P.S. \& Stutzel, T. (eds.). Flowering plants: Monocotyledons. Alismatanae and Commeliananae (except Gramineae). Vol. 4. Springer-Verlag, Berlin-Heidelberg. Pp. 275-277.

Larsen, K.; Lock, J.M.; Maas, H. \& Maas, P.J.M. 1998. Zingiberaceae. In: Kubitzi, K.; Huber, H.; Rudall, P.J.; Stevens, P.S. \& Stutzel, T. (eds.). Flowering plants: Monocotyledons. Alismatanae and Commeliananae (except Gramineae). Vol. 4. Springer-Verlag, Berlin-Heidelberg. Pp. 474-495.

Maas, P.J.M. 1972. Costoidae (Zingiberaceae). Flora Neotropica, Monograph 8: 1-139.
Melo, A.; Araújo, A.A.M. \& Alves, M. 2013. Flora da Usina São José, Igarassu, Pernambuco: Aristolochiaceae e Piperaceae. Rodriguesia 64: 543-553.

Mittermeier, R.; Myers, N. \& Mittermeier, C. 1999. Hotspots. CEMEX, Ciudad México. 431p.

Myers, N.; Mittermeier, R.; Mittermeier, C.; Fonseca, G \& Kent, J. 2000. Biodiversity hotspots for conservation priorites. Nature 403: 843-857.

Nascimento, L.M.; Rodal, M.J. \& Silva, A.G. 2012. Florística de uma floresta estacional no Planalto da Borborema, nordeste do Brasil. Rodriguesia 63: 429-440.

Oliveira, J.B. \& Leite, M.S. 2007. A Ordem Zingiberales nos Herbários do Estado de Pernambuco. Revista Brasileira de Biociências 5: 810-812.

Peixoto, A.L. \& Maia, L.C. 2013. Manual de Procedimentos para herbários. Ed. Universitária da UFPE, Recife. 96p.

Pereira, M.S. \& Alves, R.R.N. 2007. Composição Florística de um remanescente de Mata Atlântica na Área de Proteção Ambiental Barra do Rio Mamanguape, Paraíba, Brasil. Revista de Biologia e Ciências da Terra 7: 357-366.

Pessoa, E. \& Alves, M. 2012. Flora da Usina São José, Igarassu, Pernambuco: Orchdaceae. Rodriguesia 62: 341-356.

Petersen, O.G. 1890. Marantaceae. In: Martius, C.F.P. von; Eichler, A.W. \& Urban, I. Flora brasiliensis. Munchen, Wien, Leipzig. Vol. 3, pp. 81-172.

Ribeiro, M.C.; Metzger, J.P.; Martensen, A.C.; Ponzoni, F.J. \& Hirota, M.M. 2009. The Brazilian Atlantic Forest: how much is left, and how is the remaining forest distributed? Implications for conservation. Biological Conservation 142: 1141-1153.

Rodal, M.J.; Lucena, M.F.A.; Andrade, K.V.S.A. \& Melo, A.L. 2005. Mata do Toró: uma floresta estacional semidecidual de terras baixas no nordeste do Brasil. Hoehnea 32: 283-294.

Silva, A.G.; Sá-e-Silva, I.M.M.; Rodal, M.J.N. \& Lins-e-Silva, A.C. 2008. Influence of edge and topography on canopy and sub-canopy structure of an Atlantic Forest fragment in Igarassu, Pernambuco State, Brazil. Bioremediation, Biodiversity and Bioavailability 2: 41-46.

Souza, A.C.R.; Almeida Júnior, E.B. \& Zickel, C.S. 2009. Riqueza de espécies de sub-bosque em um fragmento florestal urbano, Pernambuco, Brasil. Biotemas 22: 57-66.

Specht, C.D. \& Stevenson, D.W. 2006. A new phylogenic based generic classification of Costaceae (Zingiberales). Taxon 55: 153-163.

Tabarelli, M.; Aguiar, A.V.; Ribeiro, M.C.; Metzger, J.P. \& Peres, C.A. 2010. Propects for biodiversity conservation in the Atlantic Forest: Lessons from aging human-modified landscapes. Biological Conservation 143: 2328-2340. 
Thiers, B. 2015. [continuously updated]. Index Herbariorum: A global directory of public herbaria and associated staff. New York Botanical Garden's Virtual Herbarium. Disponível em $<$ http:// sweetgum.nybg.org/ih/>. Acesso em 4 maio 2015.

Thomas, W.W. \& Barbosa, M.R.V. 2008. Natural Vegetation Types in the Atlantic Coastal Forest of Northeastern Brazil. Memoirs of the New York Botanical Garden 100: 6-20.

Trindade, M.B.; Lins-e-Silva, A.C.B.; Silva, H.P.; Figueira, S.B. \& Schessl, M. 2008. Fragmentation of the northern coastal region of Pernambuco, Brazil: Recent changes and implications for conservation. Bioremediation, Biodiversity and Bioavailability 2: $5-13$.

Yoshida-Arns, K.N; Mayo, S. \& Alves, M.C. 2002. O gênero Maranta L. (Marantaceae) no estado de Pernambuco, Nordeste do Brasil. Insula 31: 39-57.

Yoshida-Arns, K.N. 2003. Revisão taxonômica de Ctenanthe Eichler e Stromanthe Sond. (Marantaceae). Tese de Doutorado. Universidade Federal Rural de Pernambuco, Recife. 950p.

\section{Lista de exsicatas}

Andersson, L. \& Hagberg, M. s.n. CEPEC 38964 (3.5); Amorim, B.S. 872 (3.7); Alves-Araújo, A. 535 (3.7); Alves-Araújo, A. \& Araújo, D. 705 (1.1); 738 (2.3); Araújo-Alves, A. \& Araújo, D. 738 (2.3); Alves-Araújo, A. et al. 219 (3.7); 392 (3.7); 498 (3.6); 562 (3.3); 791 (3.1); 792 (3.7);Alves-Araújo A. \& Marques, J.S 835 (3.4); Araújo, D. \& Alves-Araújo, A. 551 (2.3); 535 (2.2); 537 (3.6); Araújo, D. et al. 196 (3.3); 436 (3.6); 617 (3.7); Bezerra, G.J. \& Melquíades, A. 135 (2.2); Bezerra, G.J. \& Silva, M.J. 45(3.7); Cavalcanti, D. \& Garcia, J.D. 35 (3.1); Costa Soares, C.M. 138 (2.2); Garcia-Gonzalez, J.D. 1143 (3.7); 1462 (3.2); Irapuam, J. 29 (3.7); Luna, N.K. et al. 17 (3.7); 18 (2.2); 19 (1.1); 21 (3.3); 23 (1.1); 24 (3.6); 25 (3.3); 26 (2.2); 27 (3.2); 30 (3.1); 40 (2.2); 45 (3.3); 49 (3.7); 50 (2.2); 51 (3.4); 52 (1.1); 53 (3.7); Luna, N.K. \& Maciel, J.R. 38 (2.1); Luna, N.K. \& Pessoa, E. 20 (3.5); Mariz, G. 457 (3.4); 496 (3.4); Melo, A. \& Albuquerque, N. 189 (2.2); 192 (2.2); Melo, A. et al. 9 (3.6); 57 (2.2); Melquíades, A. \& Bezerra, G.J. 81 (3.7); 158 (1.1); 176 (3.7); Melquíades et al. 24 (2.2); Nascimento, L.M. \& Batista, G. 801 (2.2); Neves, C. s.n. UFP 24678 (2.3); Ojima, P.Y. 11 (2.2); Oliveira, A. \& Silva, A.G. 1 (3.7); 2 (2.2); Pessoa et al. 70 (1.1); 73 (3.7); Pessoa, E. \& Souza, J.A.N. 148 (2.2); Pontes, T.A. 177 (1.1); Pontual, I. 77 (2.1); Sá e Silva, I.M.M. et al. 6 (2.2); 69 (2.2); 225 (2.2); Sá e Silva, I.M.M. \& Freire, S.G. 189 (1); Siqueira-Filho, J.A. 1332 (2.3); Siqueira, J.A. \& Baracho, G.S. 788/712 (2.3); Siqueira-Filho, J.A. \& Neves, C.B. 915 (2.3). 
